\title{
Microstuctural Studies Of The Chromia Stabilized Iron Oxide Water Gas Shift Catalyst
}

\author{
C.J.Kiely ${ }^{*}$, M.A.Edwards ${ }^{*}$, D.M.Whittle ${ }^{*}$, C.Rhodes ${ }^{* *}$ and G.J.Hutchings ${ }^{* *}$ \\ \# Department of Materials Science and Engineering, Lehigh University, PA 10815, USA \\ * Department of Engineering, University of Liverpool, Merseyside, L69 3BX, UK \\ ** Department of Chemistry, University of Wales, Cardiff, CF10 3TB, UK
}

Iron oxide in the form of magnetite $\left(\mathrm{Fe}_{3} \mathrm{O}_{4}\right)$ is the primary catalyst for the high temperature (310$450^{\circ} \mathrm{C}$ ) water gas shift (WGS) catalyst [1]. In use, pure $\mathrm{Fe}_{3} \mathrm{O}_{4}$ catalysts rapidly lose activity due to a reduction in surface area caused by sintering. Hence a structural stabilizer, usually $\mathrm{Ck}_{2} \mathrm{O}_{3}$, is added to industrial WGS catalysts. Various $\mathrm{Fe}_{3} \mathrm{O}_{4} / \mathrm{Cr}_{2} \mathrm{O}_{3}$ catalyst compositions have been tried, and whilst $14 \mathrm{wt} \% \mathrm{Cr}_{2} \mathrm{O}_{3}$ produces the greatest resistance to sintering, a concomitant reduction in activity per unit area means that an $8 \mathrm{wt} \% \mathrm{Cr}_{2} \mathrm{O}_{3}$ addition has been accepted as a compromise. Such stabilized catalysts can operate for 2-10 years before sintering produces a reduction in activity sufficient to require catalyst replacement. Despite the industrial significance of the WGS catalyst, some controversy still exists over how the stabilization effect is achieved. Some researchers [2] beleve the stabilization is effected by discrete $\mathrm{Cr}_{2} \mathrm{O}_{3}$ grains that physically block the sintering of neighbouring $\mathrm{Fe}_{3} \mathrm{O}_{4}$ particles. Others [3] insist that the chromium exists in solid solution in the $\mathrm{Fe}_{3} \mathrm{O}_{4}$ lattice, although they have not proposed a mechanism by which stabilization occurs. In an attempt to resolve this controversy, we have studied a freshly reduced $\mathrm{Fe}_{3} \mathrm{O}_{4} / \mathrm{Cr}_{2} \mathrm{O}_{3}$ catalyst by electron diffraction, HREM, STEM-EDS and X-ray photoelectron spectroscopy (XPS).

The $\mathrm{Fe}_{2} \mathrm{O}_{3} / \mathrm{Cr}_{2} \mathrm{O}_{3}$ catalyst precursor was prepared by co-precipitation from a solution of mixed metal nitrates. Reduction of the precursor to the freshly activated $\mathrm{Fe}_{3} \mathrm{O}_{4} / \mathrm{Cr}_{2} \mathrm{O}_{3}$ catalyst $\left(42 \mathrm{~m}^{2} \mathrm{~g}^{-1}\right)$ was carried out according to the procedure described by Lywood and Twigg [4]. The nominal bulk $\mathrm{Cr}: \mathrm{Fe}$ ratio in the catalyst was designed to be 8:92, however XPS analysis yielded a Cr:Fe ratio of 23:27 suggesting a significant surface enrichment in $\mathrm{Cr}$.

The $\mathrm{Fe}_{3} \mathrm{O}_{4} / \mathrm{Cr}_{2} \mathrm{O}_{3}$ catalyst (Fig. 1) was found to consist of dense agglomerates of irregular crystallites ranging between $10-60 \mathrm{~nm}$ in size. All the rings in the corresponding selected area electron pattern could be attributed to the $\mathrm{Fe}_{3} \mathrm{O}_{4}$ phase. A typical lattice image from the [1-14] zone axis of a magnetite crystallite is shown in Fig.2. A careful survey of the sampl by STEM-EDS analysis failed to identify any discrete $\mathrm{Cr}_{2} \mathrm{O}_{3}$ grains suggesting that the physical barrier model is not correct. Bulk analyses where the probe was rastered to encompass a large area of sample gave a $\mathrm{Cr}$ content of $8.2 \pm 0.8 \mathrm{wt} \%$, which is close to the nominal value of $8 \mathrm{wt} \%$. Point analyses were also taken through the centre and close to the very edge of 100 crystallites using a $1 \mathrm{~nm}$ probe. A summary of the results obtained is presented in Fig.3. There is a considerable variation in $\mathrm{Cr}$ content from grain-to-grain in the material and there is a clear difference in the $\mathrm{Cr}$ distribution from the centreto-edge of individual grains (Fig.4). The average centre composition was $6.3 \pm 2.3 \mathrm{wt} \%$ whereas the average edge composition was $10.7 \pm 4.8 \mathrm{wt} \%$. This difference directly confirms the existence of a $\mathrm{Cr}$ surface segregation effect. No specific correlations could be found between the measured centre and edge compositions of individual grains (i.e. a low $\mathrm{Cr}$ content at the interior of a particle did not necessarily mean a high $\mathrm{Cr}$ content at the edge). 
The $\mathrm{Cr}^{3+}$ ion can exist in solid solution within the magnetite lattice. The $\mathrm{d}^{3}$ electron configuration gives it a maximum crystal field stabilization energy factor $(\Delta=1.2)$ meaning that it will exclusively occupy octahedral interstices in the oxygen sub-lattice. The inhomogeneous $\mathrm{Cr}$ distribution noted (i) from grain-to-grain and (ii) within individual grains occurs as a consequence of the co-precipitation procedure employed, since the different metallic species involved will come out of solution over a range of $\mathrm{pH}$ values. A feasible explanation for the stabilization of $\mathrm{Fe}_{3} \mathrm{O}_{4}$ by $\mathrm{Cr}^{3+}$ may be invoked by taking the $\mathrm{Cr}$ surface segregation effect into account. The melting temperatures of $\mathrm{Cr}_{2} \mathrm{O}_{3}$ and $\mathrm{Fe}_{3} \mathrm{O}_{4}$ are $2603 \mathrm{~K}$ and $1870 \mathrm{~K}$ respectively. By virtue of the stronger $\mathrm{Cr}-\mathrm{O}$ bond, the melting point of a $\mathrm{Fe}-$ $\mathrm{Cr}-\mathrm{O}$ oxide will progressively increase with increasing $\mathrm{Cr}$ content. The $\mathrm{Cr}$ enriched surface skin that encapsulates each catalyst grain, being more thermodynamically stable than the iron-rich core, will thus very effectively reduce ion diffusion and sintering effects at the WGS reaction temperature.

[1] Lloyd L, Ridler DE and Twigg MV, Catalyst Handbook, (1989), $2^{\text {nd }}$ Edition.

[2] Chinchen GC, Logan RH and Spencer MS, Appl.Catal,12, (1984), 69.

[3] Robbins M, Wertheim GK, Sherwood Rc and Buchanan DNE, J.Phys.Chem.Sol.,32, (1971),717.

[4] Lywood JW and Twigg MV, European Patent Application, 0361648, (1990).

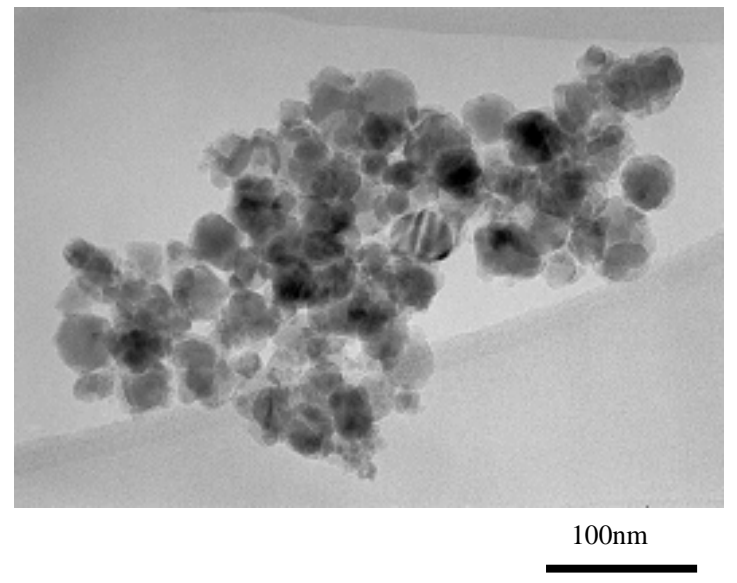

Figure 1 Bright field micrograph of the $\mathrm{Fe}_{3} \mathrm{O}_{4} / \mathrm{Cr}_{2} \mathrm{O}_{3}$ WGS catalyst

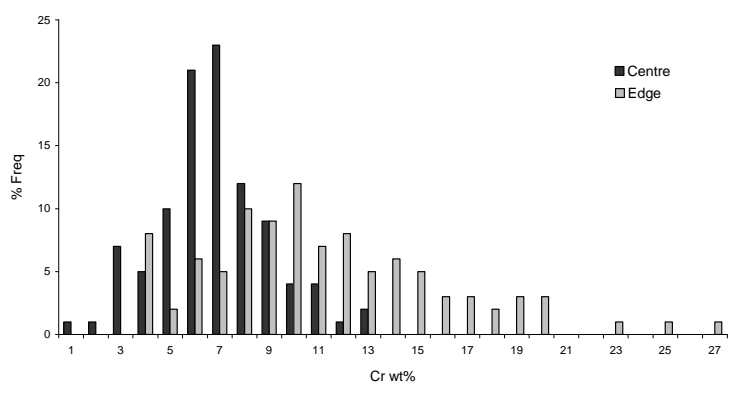

Figure 3 Histogram showing Cr content distribution measured at centre and edge of individual catalyst particles.

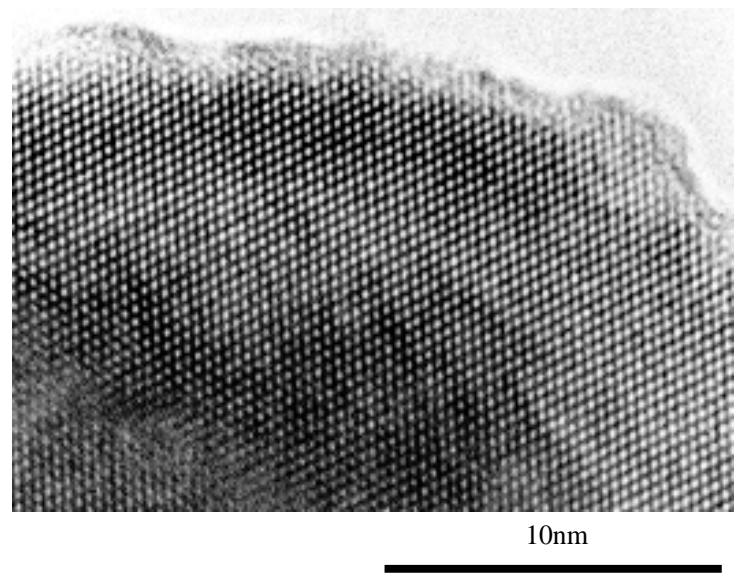

Figure 2 [1-14] HREM image of a single $\mathrm{Fe}_{3} \mathrm{O}_{4} / \mathrm{Cr}_{2} \mathrm{O}_{3}$ grain.

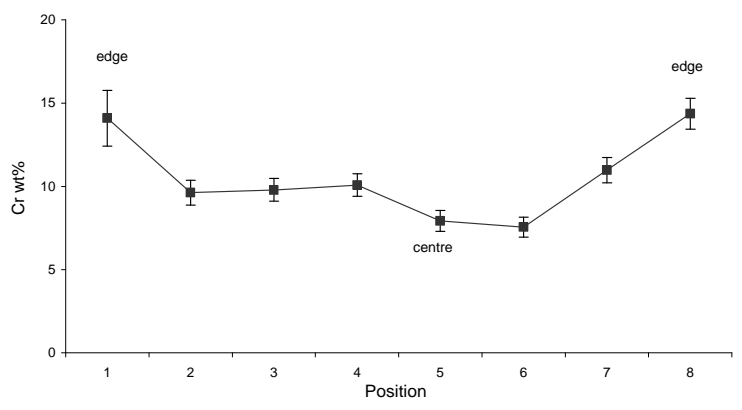

Figure $4 \mathrm{Cr}$ content measured as a function of position across the single $\mathrm{Fe}_{3} \mathrm{O}_{4} / \mathrm{Cr}_{2} \mathrm{O}_{3}$ catalyst particle. 